\title{
Demografische diversiteit in het Vlaamse perslandschap
}

\section{Inleiding}

'We willen net geen oude mannen in witte jassen aan het woord laten in het nieuws over wetenschap. Er zijn genoeg jonge onderzoekers bezig met wetenschap, ook vrouwen' (Wauters, 20I3). Hiermee toont Vlaams journalist Koen Wauters aan dat diversiteit vandaag de dag op de journalistieke agenda staat. Deze studie onderzoekt in welke mate dit engagement resulteert in een divers beeld van personen in de Vlaamse dagbladen op het vlak van leeftijd, gender en etniciteit.

Diversiteit wordt gezien als een kenmerk van de westerse samenleving, waarbij vanuit een normatief uitgangspunt de media de taak hebben om die verscheidenheid te weerspiegelen (McQuail, I992). Toegepast op nieuwsinhoud, veronderstelt deze taakomschrijving dat nieuwsberichten de demografische diversiteit in de samenleving voldoende reflecteren. Dat iedereen, of ten minste iedere relevante 'groep', in het nieuws dient te worden afgebeeld, hangt samen met de eventuele toegang tot macht. Immers, wie in het nieuws aan bod komt, is zichtbaar; wie integendeel geen forum krijgt, verdwijnt als het ware in de machteloze vergetelheid. Nieuwsmedia kunnen dan ook ongelijkheden en machtsrelaties op het vlak van gender, etniciteit en leeftijd in hun representaties bestendigen, ontkrachten of versterken (Orgad, 20I2).

\section{Diversiteit van belang?}

In de literatuur is de conceptualisering van 'diversiteit' vaak een heikel punt, omdat het een breed begrip is met vele ladingen en betekenissen. Dit onderzoek analyseert

* Hanne Vandenberghe is wetenschappelijk medewerker aan het Instituut voor Mediastudies, KU Leuven. Contactgegevens: Parkstraat 45 bus 3603, 3000 Leuven, België. Tel.: +32 I6 3232 29, fax: +32 I6 3204 97. hanne.vandenberghe@soc.kuleuven.be

Leen d'Haenens is gewoon hoogleraar aan het Instituut voor Mediastudies, KU Leuven. Contactgegevens: Parkstraat 45 bus 3603, 3000 Leuven, België. Tel.: +32 I6 3236 20, fax: +32 I6 320497 . leen.dhaenens@soc.kuleuven.be

Baldwin Van Gorp is hoofddocent aan het Instituut voor Mediastudies, KU Leuven. Contactgegevens: Parkstraat 45 bus 3603, 3000 Leuven, België. Tel.: +32 I6 32 3I 79, fax: +32 I6 3204 97. baldwin.van gorp@soc.kuleuven.be 
de diversiteit van personen op het vlak van leeftijd, gender en etniciteit in de Vlaamse pers. Uit voorgaand onderzoek blijkt dan ook dat wie aan bod komt in de (nieuws)media verband houdt met het al dan niet behoren tot de samenleving. Door bijvoorbeeld vrouwen systematisch minder dan mannen af te beelden, geven de media aan dat vrouwen een minder prominente rol in de maatschappij spelen dan mannen. Dit wordt symbolic annihilation of sociale exclusie genoemd: door een bepaalde groep niet of enkel in specifieke contexten of rollen voor te stellen, bepalen de media hun sociale positie (Silverstone, 2008). Voor etnisch-culturele minderheden komt daarbij dat voor een groot deel van de bevolking nieuwsmedia de belangrijkste, of zelfs enige informatie- en kennisbron zijn over deze minderheidsgroepen. Een ondervertegenwoordiging van experts van etnisch 'gekleurde' origine versterkt dan ook de idee dat een 'verstandige' en 'beschaafde' meerderheid de 'onwetende' minderheid moet informeren (Hussain, 2000). Voor de integratie van een groep in de samenleving is aan bod komen in de media cruciaal. Door bepaalde groepen te weinig te representeren, krijgen ze onvoldoende de kans zich in de samenleving te integreren, hetgeen een negatieve invloed heeft op alle leden van een samenleving (Trebbe \& Schoenhagen, 20II). Immers, democratisch werkende media verspreiden verscheidene standpunten van een divers aantal bronnen zodat publiek debat mogelijk is en burgers beter geïnformeerd en geïntegreerd zijn (Duncan \& Reid, 20I3).

\section{Diversiteit als afspiegeling van de werkelijkheid}

Dit onderzoek vertrekt vanuit de normatieve reflectionistische visie op mediarepresentatie die stelt dat de media de werkelijkheid als een spiegel dienen te reflecteren (McQuail, I992). Het ijkpunt voor diversiteit is in deze interpretatie de maatschappelijke diversiteit. Media worden in dit opzicht gezien als onderdeel van de cultuur, waarbij cultuur staat voor 'de gedeelde gebruiken, overtuigingen, normen en waarden die aan een collectiviteit haar samenhang verlenen - op het niveau van samenlevingen als geheel of dat van kleinere groepen' (Van Zoonen, 2007, p. 6). De constructivistische stroming bekritiseert echter dit weerspiegelingsidee (Orgad, 20I2). Constructivisten zien namelijk elke representatie als een vervormd construct van een werkelijkheid waardoor media onmogelijk de werkelijkheid in hun inhouden kunnen representeren. Dé 'objectieve' werkelijkheid bestaat volgens deze visie niet; deze is slechts een constructie van het moment. Binnen die constructie van de werkelijkheid zijn de bestaande maatschappelijke verhoudingen cruciaal: bepaalde groepen hebben meer invloed dan andere. En net daarbij spelen de media een actieve rol: zij kunnen bepaalde groepen meer of minder aandacht geven en dus meer of minder invloed op de werkelijkheid laten uitoefenen.

Deze studie interpreteert diversiteit als inhoudsdiversiteit; media moeten de verschillende sociale groepen in de samenleving een stem geven zodat burgers een breed aanbod aan ideeën en perspectieven krijgen. Concreet wordt inhoudsdiversiteit geo- 
perationaliseerd als demografische diversiteit, dat wil zeggen de mate waarin de Vlaamse pers personen wat betreft hun leeftijd, gender en etniciteit proportioneel met de demografische werkelijkheid afbeeldt. Deze oefening wordt zowel uitgevoerd voor alle personen in het nieuws, alsook specifiek voor de nieuwsbronnen. Dit geldt als meting voor bronnendiversiteit, hetgeen staat voor nieuwsinhoud waarbij diverse en tegengestelde bronnen het woord krijgen (Napoli, 1999).

Van journalisten kan vanuit deze visie worden verwacht dat zij de sociale realiteit zo goed mogelijk weergeven. Precies door feiten vanuit verschillende perspectieven in het nieuws aan te bieden, maakt de journalist gebruik van bronnendiversiteit. Deze studie gaat uit van een bestaande werkelijkheid die journalisten mee construeren door de manier waarop ze erover berichten. Nieuwsmedia zijn daarbij moderne instandhouders van groepsclassificaties, aangezien personen met een machtsfunctie gemakkelijker toegang tot de media krijgen en zo meebepalen wat belangrijk is in de samenleving. Op die manier bepalen zij wie tot de samenleving behoort ('wij') en wie niet ('zij') (o.a. Orgad, 2012; Van Zoonen, 2007).

De diversiteit in het nieuws nagaan met als benchmark de populatiegegevens geldt als theoretisch uitgangspunt en niet als richtlijn voor journalisten. Om de mate van diversiteit te kunnen beoordelen, is een dergelijk referentiepunt noodzakelijk. Bovendien kan het ook als startpunt voor diversiteitsmeting fungeren, waarna de evolutie van diversiteit kan worden gemonitord. Het is mogelijk de meting bij de verschillende stakeholders af te toetsen en er het mediabeleid rond op te bouwen (Duncan \& Reid, 2013). Deze studie brengt de huidige inhoudsdiversiteit in de Vlaamse kranten in kaart, wat als leidraad kan dienen voor het mediabeleid omtrent diversiteit.

De vertekening tussen werkelijkheid en media meten blijft voor interpretatie vatbaar (Groeling, 20I3). Wat houdt die werkelijkheid precies in? In het geval van nieuws is dit een selectie van feiten die nieuwsmakers als nieuwswaardig bestempelen. Deze feiten zijn dus een selectie van de werkelijkheid en geen volledige weerspiegeling ervan. Methodisch rijst hier een probleem: er zijn geen demografische gegevens beschikbaar voor de verschillende takken in de samenleving. Zo is het voor het nieuwsthema welzijn moeilijk haalbaar een vergelijking te maken met de werkelijke verdeling van mannen en vrouwen werkzaam binnen de welzijnsbranche.

Uit talrijke studies blijkt dat journalisten zich meer op professionele bronnen baseren, aangezien deze bronnen de nodige autoriteit hebben om de analyses over de gepresenteerde feiten te legitimeren (Albæk, 20II). Deze journalistieke reflex houdt de symbolische machtsstructuren in stand: personen met macht krijgen in het nieuws meer het woord, waardoor hun mening als belangrijker wordt beschouwd; traditioneel zijn in een westerse context dergelijke experts volwassen 'blanke' mannen. Dit impliceert dat de maatschappelijke diversiteit wat betreft elitepersonen hoe 
dan ook weinig divers zal zijn. Binnen de journalistieke wereld is er wel meer aandacht om de 'gewone man' als nieuwsbron aan het woord laten, vermits dit de identificatie van de lezer met het nieuws, en dus met het medium zou kunnen vervorderen (Albæk, 20II). Deze 'gewone man' is een representatie van 'iedereen', wat de vergelijking van diversiteit in het nieuws met de bevolkingscijfers meer relevant maakt.

\section{Diversiteit onderzocht}

Uit de (inter)nationale literatuur blijkt dat leeftijd, gender en etniciteit disproportioneel in het nieuws voorkomen. In Zuid-Afrikaanse nieuwsmedia kwamen bijvoorbeeld $6 \%$ jongeren voor in tegenstelling tot de demografische werkelijkheid van 39,4\% (Ponte, 2007). Daarnaast werden vrouwen significant ondervertegenwoordigd in de Spaanse kwaliteitskrant El Mundo alsook in twee Amerikaanse dagbladen (Len-Ríos, Rodgers, Thorson \& Yoon, 2005; Matud, Rodríguez \& Espinosa, 20II). In het Vlaamse televisienieuws werd in twee op de vijf nieuwsitems een vrouw als bron opgevoerd (De Swert \& Hooghe, 20IO). Etnisch-culturele minderheden tot slot kwamen in een Europese krantenstudie in $5 \%$ van de nieuwsverhalen voor. Specifiek in verhalen over etnisch-culturele minderheden waren twee op de drie nieuwsbronnen 'wit' (Ter Wal, d'Haenens \& Koeman, 2005). In het Vlaamse televisienieuws domineerden etnisch-culturele minderheden nipt (54\%) in nieuwsverhalen die over hen handelden (Van den Bulck \& Broos, 20II).

Herhaaldelijk werd in eerder onderzoek vastgesteld dat bepaalde groepen in de nieuwsmedia worden ondervertegenwoordigd. Deze studie verwacht dat ouderen, jongeren, vrouwen en etnisch-culturele minderheden in de Vlaamse pers anno 2012 in verhouding tot de werkelijkheid worden ondervertegenwoordigd:

Hi: In de Vlaamse dagbladpers zullen jongeren en ouderen als actor en als nieuwsbron ondervertegenwoordigd zijn in verhouding met hun relatieve voorkomen in de realiteit.

H2: In de Vlaamse dagbladpers zullen vrouwen als actor en als nieuwsbron ondervertegenwoordigd zijn in verhouding met hun relatieve voorkomen in de realiteit.

H3: In de Vlaamse dagbladpers zullen etnisch-culturele minderheden als actor en als nieuwsbron in de binnenlandse berichtgeving ondervertegenwoordigd zijn in verhouding met hun relatieve voorkomen in de Belgische samenleving.

De weerspiegeling van etniciteit in de Vlaamse pers wordt enkel geanalyseerd in de binnenlandse berichtgeving (d.w.z. nieuws dat over België of Belgen handelt). Zodoende is een zinvolle vergelijking met 'real-life' data mogelijk. Etniciteit is namelijk specifiek verbonden met een land of regio: een Belg die emigreert naar 
Marokko wordt in Marokko bijvoorbeeld als een etnisch-culturele minderheid beschouwd.

Dat het nieuws iedere 'groep' in de maatschappij representeert, is een minimale vereiste voor diversiteit. Des te belangrijker is de context waarin deze 'groepen' worden voorgesteld. Een proportionele man-vrouwverdeling in het nieuws staat immers niet garant voor een diverse berichtgeving; de verscheidenheid aan nieuwsthema's of functies waarin vrouwen en mannen een stem krijgen, speelt ook een rol. Deze studie analyseert dan ook de contexten waar personen in voorkomen. Uit twee Vlaamse studies blijken Belgen van Turkse of Marokkaanse origine het als problematisch te ervaren steevast in verband met dezelfde nieuwsonderwerpen te worden afgebeeld. Ze herkennen zich niet in het gepresenteerde stereotiepe portret over hun 'groep' en zien het nieuws als niet representatief in verhouding tot hun leefwereld. Ze stellen het nieuws dan ook medeverantwoordelijk voor de heersende vooroordelen over hun 'groep' (Devroe, Driessens, \& Verstraeten, 20Io; El Sghiar \& d'Haenens, 20II).

Uit tal van (inter)nationale studies blijkt dat journalisten etnisch-culturele minderheden in specifieke problematiserende contexten afbeelden. In de Deense binnenlandse berichtgeving werden etnisch-culturele minderheden overwegend voorgesteld als criminelen. Ze kregen weinig zelf het woord. Er werd namelijk bij monde van hoofdzakelijk politici en politie over hen gesproken. Wanneer ze als bron werden opgevoerd, was dit binnen een etnische context, waarbij vrouwen bijna uitsluitend geportretteerd werden als slachtoffers van hun cultuur (Hussain, 2000). Ook uit een Europese landenvergelijkende inhoudsanalyse van kranten bleek dat de etnisch getinte nieuwsverhalen overwegend over criminaliteit en veiligheid gaan (Ter Wal et al., 2005). De Vlaamse kranten en televisiejournaals vertonen dezelfde trend (Devroe, 2007; Van den Bulck \& Broos, 20II).

Het systematisch in bepaalde rollen en verhalen voorkomen in het nieuws is evenzeer het geval voor kinderen en vrouwen. In de Portugese pers werden kinderen onder de I4 jaar in het binnenlands nieuws vooral binnen een onderwijscontext afgebeeld, terwijl de buitenlandse nieuwspagina's hen voorstelden als slachtoffers van oorlogen en natuurrampen (Ponte, 2007). In twee Amerikaanse kranten kwamen vrouwen significant meer voor in entertainmentnieuws, en minder in business- en sportnieuws (Len-Ríos et al., 2005). In het Vlaamse televisienieuws kwamen vrouwen $20 \%$ minder voor in zogenoemde 'mannelijke' onderwerpen zoals politiek dan in zogenoemde 'vrouwelijke' topics zoals cultuur (De Swert \& Hooghe, 20I0). Vlaamse vrouwelijke politici bleken daarnaast in die vrouwelijke thema's ook minder spreektijd te hebben dan hun mannelijke collega's (Vos, 20I2).

Op basis van bovenstaande literatuur worden de volgende hypothese en onderzoeksvraag vooropgesteld: 
$\mathrm{H}_{4}$ : In de Vlaamse dagbladpers komen jongeren, ouderen, vrouwen, en etnischculturele minderheden in bepaalde nieuwsthema's meer voor dan in andere. OV5: Hoe komen deze 'groepen' voor in de Vlaamse dagbladpers: als elitebron, als getuige of 'vox populi'?

\section{Methodologie}

De steekproef bestaat uit een geconstrueerde week uit het voorjaar van 2012 (3 april tot en met 9 mei) van de volgende kranten: De Morgen, De Standaard, De Tijd, Metro, Het Belang van Limburg, Gazet van Antwerpen, Het Nieuwsblad en Het Laatste Nieuws $(N=4800)$. Een toevalssteekproef van een geconstrueerde week is voldoende om een volledig nieuwsjaar te representeren (Riffe, Lacy \& Fico, I998). De zesdaagse steekproef werd omwille van praktische overwegingen uit zes opeenvolgende weken geselecteerd. Bovendien werd telkens de gehele krant geanalyseerd, met uitzondering van opiniebijdrages zoals columns en lezersbrieven, en de regionale katern per editie. Regionaal nieuws dat niet exclusief voor één editie bestemd was, werd wel mee opgenomen in de steekproef.

In totaal werden I2.743 personen vermeld in de geanalyseerde nieuwsverhalen. De groep personen die enkel met naam en/of functie werden vermeld, zijn de actoren: er wordt over de actor geschreven, maar hij/zij spreekt niet zelf. De nieuwsbronnen zijn alle actoren die zelf het woord krijgen, doordat journalisten hen letterlijk citeren of parafraseren. De steekproef bevatte $6 \mathrm{I}, 6 \%$ actoren $(n=7849)$ en $38,4 \%$ nieuwsbronnen $(n=4894)$. Alle actoren werden vervolgens zo objectief mogelijk ingedeeld naargelang hun leeftijd, gender en etniciteit.

Leeftijd werd onderverdeeld in drie vooropgestelde categorieën: (I) jongeren zijn niet ouder dan I8 jaar; (2) volwassenen zijn tussen de I8 en 64 jaar oud; en (3) ouderen zijn 65-plussers. De indeling gebeurde op basis van expliciete leeftijdsvermelding of tekstuele informatie (bijv. 'emeritus' is oudere). Bij $85,5 \%$ van alle personen kenden de codeurs een leeftijdsgroep toe ( $n=$ Io.890).

Gender werd ingedeeld op basis van naamsherkenning (bijv. 'Piet' is man) of tekstuele informatie (bijv. 'woordvoerster' is vrouw). Bij 96,8\% van alle personen ( $n=$ ı2.337) werd geslacht gemeten.

Bij etniciteit werd een onderscheid gemaakt tussen etnisch-culturele minder- en meerderheden. Etnisch-culturele minderheden worden gedefinieerd als individuen van wie op basis van de tekstuele informatie in het krantenbericht kan worden afgeleid dat zijzelf of hun (voor)ouders roots hebben buiten de EU-I5 (zie Devroe, 2007; Van den Bulck \& Broos, 20II). In eerste instantie werden alle vermeldingen van nationaliteit of een afgeleide ervan (bijv. 'Catalaans') opgelijst. In het binnenlands 
nieuws werd slechts bij 6,8\% van alle actoren $(n=34 \mathrm{I})$ expliciet naar nationaliteit verwezen. Personen werden daarom eveneens ingedeeld op basis van naamsherkenning. Alle westers aandoende namen werden onderverdeeld als EU-I5 (bijv. 'Elio Di Rupo'). Bij twijfelgevallen en indien bovendien de nationaliteit niet vermeld stond, werd de persoon gecategoriseerd als onbekend (bijv. 'Jeffrey Alenus'). Alle Engelstalige namen werden gecodeerd als westers, tenzij expliciet een niet-EU-I5-nationaliteit werd vermeld. Alle niet-westers aandoende namen (bijv. 'Elif Tek') werden als niet-EU-I5 beschouwd. De codering gebeurde zoals de doorsnee imaginaire lezer een vreemd klinkende naam als behorende tot een etnisch-culturele minderheid kan beschouwen. Bij 9I,2\% van de actoren $(n=458 \mathrm{I})$ werd op die manier etniciteit ingeschat.

De relatieve verhoudingen van leeftijd, gender en etniciteit werden afgewogen tegen de bevolkingsgegevens. Alleen voor etniciteit beperkt deze vergelijking zich tot het binnenlandse nieuws, voor leeftijd en gender gebeurt dit voor de gehele berichtgeving. In 2012 telde de Belgische samenleving 9\% etnisch-culturele minderheden. Mannen en vrouwen zijn zowel wereldwijd (49,6\% vrouwen en 50,4\% mannen) als in België (50,9\% vrouwen en 49,1\% mannen) gelijk vertegenwoordigd. Wereldwijd zijn ongeveer drie op vijf personen volwassen (35,6\% jongeren, $56,8 \%$ volwassenen en $7,6 \%$ ouderen). Dit geldt ook voor België $(20,4 \%$ jongeren, $63,5 \%$ volwassenen en $\mathrm{I} 6, \mathrm{I} \%$ ouderen); hoewel hier de groep ouderen groter en de groep jongeren kleiner is (Eurostat, 20I2; United Nations, 20II).

Als eenduidige diversiteitsmaat werd voor de drie kenmerken (leeftijd, gender en etniciteit) Simpson's $D\left(=\mathrm{I}-\sum \mathrm{p}_{\mathrm{i}}{ }_{\mathrm{i}}\right)$ berekend, waarbij $\circ$ geldt als minimale en 0,50 als maximale diversiteit (McDonald \& Dimmick, 2003). Er werd daarbij een afweging gemaakt tussen de Simpson's $D$ op basis van de populatiegegevens met de Simpson's $D$ in de Vlaamse kranten.

Daarnaast werd elke nieuwsbron ingedeeld in drie vooropgestelde categorieën: (I) elitebronnen krijgen het woord omwille van hun expertise of status (bijv. politicus); (2) getuigen bezitten relevante of exclusieve informatie over het nieuwsfeit (bijv. slachtoffer); en (3) 'vox populi' zijn zogenoemde personen in de straat, ze worden toevallig door de journalist gekozen om hun mening of ervaring te delen en zijn inwisselbaar met iemand anders (bijv. toeschouwer van een voetbalwedstrijd). De nieuwsbronnen verdeelden zich in de steekproef als volgt: 88,7\% elitebronnen $(n=$ II.300), 9,4\% getuigen ( $n=\mathrm{I} 200$ ) en I,9\% 'vox populi' $(n=243)$. De Vlaamse journalisten halen in lijn met voorgaand onderzoek (Albæk, 20II) vooral elitebronnen aan, maar blijken niet veel mannen in de straat aan het woord te laten ter identificatie van de nieuwsfeiten door de lezer.

Aan elk nieuwsartikel werd één inhoudelijk hoofdthema toegekend. De drie dominante thema's in het Vlaamse nieuws zijn sportnieuws $(28,5 \%)$, cultureel en enter- 
tainmentnieuws (16,5\%), en economisch nieuws (16,1\%). Daarna volgt nieuws over gerecht en criminaliteit (II,8\%), politiek $(7, \mathrm{I} \%)$, rampen en mobiliteit $(5,3 \%)$, welzijn $(4,4 \%)$, en internationaal beleid $(3,6 \%)$. Tot slot is er het minst nieuwsaandacht voor de thema's natuur $(2,6 \%)$, onderwijs en wetenschap $(2,6 \%)$, en rechten en vrijheden $(1,5 \%)$.

Het codeerinstrument werd via een pre-test uitgewerkt met voorbeelden, waarna alle codeurs dezelfde training kregen. Dit leverde voor alle variabelen voor een steekproef van $5,5 \%$ van de gecodeerde actoren in de nieuwsartikelen (700 personen) uitstekende intercodeurbrouwbaarheidsscores (Krippendorff's Alpha) op (Hayes \& Krippendorff, 2007): gender en nationaliteit (beiden $\alpha=$.97), leeftijd ( $\alpha$ $=$.93), opdeling in bronnencategorieën $(\alpha=$.93) en hoofdthema $(\alpha=.9 \mathrm{I})$.

\section{Resultaten}

Eerst wordt per krant gekeken naar de verdeling van leeftijd, gender en etniciteit. Leeftijd wordt binnen de Vlaamse kranten significant anders verdeeld, $\chi^{2}$ (I4) = 72,77; $p<.001$. De journalisten van Het Laatste Nieuws voeren zowel het meest aantal ouderen als jongeren op, terwijl De Tijd het meest aantal volwassenen aan bod laat komen (tabel I). Kwaliteits- en publiekskranten brengen leeftijd dan ook significant verschillend in beeld, $\chi^{2}(2)=\mathrm{I} 2,03 ; p<.005$. Publiekskranten brengen gemiddeld meer jongeren naar voren dan kwaliteitskranten (3\% in verhouding tot $1,9 \%$ ), terwijl kwaliteitskranten net iets meer ouderen $(2,4 \%)$ opvoeren dan publiekskranten $(2,3 \%)$. Tabel I toont eveneens aan dat De Morgen het meest aantal vrouwen weergeeft, terwijl Het Nieuwsblad het meest aantal mannelijke actoren opvoert. Ook voor gender verschillen de kranten onderling significant van elkaar, $\chi^{2}(7)=27, \mathrm{I} 4$; $p<$.००I. De kwaliteitskranten blijken significant meer vrouwen (I7,8\%) dan de publiekskranten $\left(\mathrm{I}_{5}, 6 \%\right)$ te vermelden, $\chi^{2}(\mathrm{I})=9,60 ; p<.005$. De verschillen tussen de kranten zijn ook op het vlak van etniciteit significant, $\chi^{2}(7)=39,37$; $\mathrm{p}<$. .o I (tabel I). Gazet van Antwerpen voert het vaakst etnisch-culturele minderheden op, terwijl De Tijd er amper weergeeft. Publiekskranten geven significant meer etnischculturele minderheden (I4,3\%) weer dan kwaliteitskranten $(7,9 \%)$ weer, $\chi^{2}(\mathrm{I})=$ 3I,28; $p<$. OOI. 
TABEL 1. Frequentie (in percentages) van actoren volgens leeftijd, gender en etniciteit opgedeeld per krant in Vlaamse krantenartikelen $(N=4800)$

\begin{tabular}{|c|c|c|c|c|c|c|c|c|}
\hline & \multicolumn{3}{|c|}{ Kwaliteitskranten } & \multicolumn{5}{|c|}{ Publiekskranten } \\
\hline & DM & DS & De Tijd & NB & HLN & GvA & BvL & Metro \\
\hline \multicolumn{9}{|l|}{ Leeftijd $^{\mathrm{I}}$} \\
\hline Jongeren & 2,0 & 2,6 & 0,2 & 3,7 & 4,3 & $\mathrm{I}, 6$ & 2,4 & $\mathrm{I}, 6$ \\
\hline Volwassenen & $9^{6, \mathrm{I}}$ & 94,3 & 97,9 & 94,4 & 92,5 & 96,7 & 95,4 & 96,8 \\
\hline Ouderen & 2,0 & $3, \mathrm{I}$ & 2,0 & $\mathrm{I}, 9$ & 3,2 & $\mathrm{I}, 7$ & 2,2 & $\mathrm{I}, 6$ \\
\hline Totaal & $\begin{array}{l}\text { I00 } \\
\text { (1625) }\end{array}$ & $\begin{array}{l}\text { Io० } \\
\text { (I247) }\end{array}$ & $\begin{array}{l}100 \\
(606)\end{array}$ & $\begin{array}{l}\text { IO० } \\
\text { (I9OI) }\end{array}$ & $\begin{array}{l}\text { IOO } \\
\text { (I9I8) }\end{array}$ & $\begin{array}{l}\text { I0O } \\
\text { (I403) }\end{array}$ & $\begin{array}{l}\text { I0० } \\
\text { (1689) }\end{array}$ & $\begin{array}{l}\text { IO० } \\
(5 \circ \mathrm{I})\end{array}$ \\
\hline \multicolumn{9}{|l|}{ Gender $^{2}$} \\
\hline Mannen & 80,5 & 83,3 & $84, \mathrm{I}$ & 85,8 & 83,7 & 85,5 & 83,3 & $8 \mathrm{I}, 6$ \\
\hline Vrouwen & 19,5 & 16,7 & I5,9 & $\mathrm{I} 4,2$ & 16,3 & $\mathrm{I} 4,5$ & 16,7 & I 8,4 \\
\hline Totaal & $\begin{array}{l}\text { IO० } \\
\text { (I8०8) }\end{array}$ & $\begin{array}{l}\text { IOO } \\
\text { (I440) }\end{array}$ & $\begin{array}{l}\text { I0० } \\
(703)\end{array}$ & $\begin{array}{l}\text { I0O } \\
(2 \mathrm{I} 25)\end{array}$ & $\begin{array}{l}\text { IOO } \\
(2 \mathrm{I} 40)\end{array}$ & $\begin{array}{l}\text { IoO } \\
\text { (1598) }\end{array}$ & $\begin{array}{l}\text { IOO } \\
\text { (I93I) }\end{array}$ & $\begin{array}{l}\text { I00 } \\
(592)\end{array}$ \\
\hline \multicolumn{9}{|l|}{ Etniciteit ${ }^{3}$} \\
\hline Etnisch-cult. meerderheid & $9 \mathrm{I}, 9$ & 90,4 & 98,6 & 85,0 & $86, \mathrm{I}$ & 85,2 & $86, \mathrm{I}$ & 88,2 \\
\hline Etnisch-cult. minderheid & $8, \mathrm{I}$ & 9,6 & $\mathrm{I}, 4$ & I5, O & 13,9 & $\mathrm{I} 4,8$ & 13,9 & II, 8 \\
\hline Totaal & $\begin{array}{l}\text { IOO } \\
\text { (52I) }\end{array}$ & $\begin{array}{l}\text { I0O } \\
(456)\end{array}$ & $\begin{array}{l}\text { I00 } \\
\text { (I42) }\end{array}$ & $\begin{array}{l}\text { IOO } \\
(878)\end{array}$ & $\begin{array}{l}\text { IOO } \\
(846)\end{array}$ & $\begin{array}{l}100 \\
(655)\end{array}$ & $\begin{array}{l}\text { IOO } \\
(922)\end{array}$ & $\begin{array}{l}\text { I00 } \\
\text { (I6I) }\end{array}$ \\
\hline
\end{tabular}

Noten. De getallen tussen haakjes zijn de absolute aantallen; de percentages bij etniciteit beperken zich tot het binnenlands nieuws $(n=202 \mathrm{I})$.

${ }^{\mathrm{I}} \chi^{2}(\mathrm{I} 4)=72,77 * * * ;{ }^{2} \chi^{2}(7)=27, \mathrm{I} 4 * * * ; \chi^{2}(7)=39,37 * * *$ met $* * * p<.00 \mathrm{I}$

\section{Leeftijd}

Van alle actoren van wie de codeurs leeftijd vaststelden ( $n=10.890)$, is $95, \mathrm{I} \%$ een volwassene, 2,6\% een jongere en $2,3 \%$ een oudere. In vergelijking met de reële sleutel van drie op vijf volwassenen blijkt deze groep het Vlaamse nieuws sterk te domineren. Voor de subcategorie nieuwsbronnen werd bij 88,5\% de leeftijdsgroep bepaald ( $n=4333)$ en vertoont de verhouding van de leeftijdsgroepen dezelfde tendens: $96,6 \%$ volwassenen, $2,2 \%$ ouderen en I,2\% jongeren. De Simpson's $D$ voor alle actoren is 0,09 en specifiek voor nieuwsbronnen 0,07 , terwijl in werkelijkheid de Simpson's $D$ gelijk is aan 0,54 ; dit betekent dat de pers 5,8 keer minder divers is wat actoren betreft en 8,2 keer minder divers voor de nieuwsbronnen. Wordt er gekeken naar enkel de actoren in het binnenlands nieuws $(n=4434,88,3 \%$ van de actoren), dan is leeftijd gelijklopend verdeeld: 95,2\% volwassenen, 2,7\% jongeren en $2,2 \%$ ouderen. De resultaten tonen aan dat volwassenen disproportioneel in verhouding tot de werkelijkheid de Vlaamse dagbladpers domineren als actor en als nieuwsbron (Нı). 
TABEL 2. Frequentie (in percentages) van actoren volgens leeftijd, gender en etniciteit opgedeeld per nieuwsthema in Vlaamse krantenartikelen $(N=4800)$

\begin{tabular}{|c|c|c|c|c|c|c|c|c|c|c|c|}
\hline & Sport & $\begin{array}{l}\text { Cul- } \\
\text { tuur en } \\
\text { enter- } \\
\text { tain- } \\
\text { ment }\end{array}$ & $\begin{array}{l}\text { Eco- } \\
\text { nomie }\end{array}$ & $\begin{array}{l}\text { Gerecht } \\
\text { en cri- } \\
\text { minali- } \\
\text { teit }\end{array}$ & Politiek & $\begin{array}{l}\text { Rampen } \\
\text { en } \\
\text { mobili- } \\
\text { teit }\end{array}$ & $\begin{array}{l}\text { Wel- } \\
\text { zijn }\end{array}$ & $\begin{array}{l}\text { Inter- } \\
\text { natio- } \\
\text { naal } \\
\text { beleid }\end{array}$ & $\begin{array}{l}\text { Onder- } \\
\text { wijs en } \\
\text { weten- } \\
\text { schap }\end{array}$ & Natuur & $\begin{array}{l}\text { Rech- } \\
\text { ten en } \\
\text { vrij- } \\
\text { heden }\end{array}$ \\
\hline \multicolumn{12}{|l|}{ Leeftijd $^{\mathrm{I}}$} \\
\hline Jongeren & $\mathrm{I}, 4$ & 4,3 & 0,5 & 5,3 & 0,8 & 5,7 & $8, \mathrm{I}$ & 3,5 & 3,5 & - & 0,6 \\
\hline $\begin{array}{l}\text { Volwasse- } \\
\text { nen }\end{array}$ & 98,2 & 90,2 & $98, \mathrm{I}$ & $9 \mathrm{I}, \mathrm{I}$ & 96,0 & 87,5 & 90,0 & 93,9 & 95,9 & 99,4 & $98, \mathrm{I}$ \\
\hline Ouderen & 0,4 & 5,5 & $\mathrm{I}, 4$ & 3,6 & $3, \mathrm{I}$ & 6,8 & $\mathrm{I}, 9$ & 2,6 & 0,6 & 0,6 & $\mathrm{I}, 2$ \\
\hline Totaal & $\begin{array}{l}100 \\
(4280)\end{array}$ & $\begin{array}{l}\text { Io० } \\
\text { (I778) }\end{array}$ & $\begin{array}{l}\text { I00 } \\
\text { (979) }\end{array}$ & $\begin{array}{l}\mathrm{I00} \\
\text { (1263) }\end{array}$ & $\begin{array}{l}\text { I00 } \\
(958)\end{array}$ & $\begin{array}{l}100 \\
(369)\end{array}$ & $\begin{array}{l}\text { IOO } \\
\text { (42I) }\end{array}$ & $\begin{array}{l}\text { I00 } \\
(347)\end{array}$ & $\begin{array}{l}\text { IOO } \\
\text { (I72) }\end{array}$ & $\begin{array}{l}\mathrm{IOO} \\
(\mathrm{I} 62)\end{array}$ & $\begin{array}{l}\text { IOO } \\
\text { (I6I) }\end{array}$ \\
\hline \multicolumn{12}{|l|}{ Gender $^{2}$} \\
\hline Mannen & $9^{6,0}$ & $7 \mathrm{I}, \mathrm{I}$ & 83,3 & $7 \mathrm{I}, 9$ & $85, \mathrm{I}$ & 77,3 & 60,6 & $82, \mathrm{I}$ & 75,9 & 75,0 & 73,7 \\
\hline Vrouwen & 4,0 & 28,9 & $\mathrm{I} 6,7$ & $28, \mathrm{I}$ & $\mathrm{I} 4,9$ & 22,7 & 39,4 & 17,9 & $24, \mathrm{I}$ & 25,0 & 26,3 \\
\hline Totaal & $\begin{array}{l}\text { IOO } \\
(490 \text { I) }\end{array}$ & $\begin{array}{l}\text { I00 } \\
(2204)\end{array}$ & $\begin{array}{l}\text { IOO } \\
\text { (I028) }\end{array}$ & $\begin{array}{l}\text { I00 } \\
\text { (1390) }\end{array}$ & $\begin{array}{l}\text { IOO } \\
\text { (1052) }\end{array}$ & $\begin{array}{l}\text { I00 } \\
(397)\end{array}$ & $\begin{array}{l}\text { I0O } \\
\text { (43I) }\end{array}$ & $\begin{array}{l}\text { IOO } \\
(4 \mathrm{I} 4)\end{array}$ & $\begin{array}{l}\text { IOO } \\
\text { (I70) }\end{array}$ & $\begin{array}{l}\text { I00 } \\
\text { (164) }\end{array}$ & $\begin{array}{l}\text { I00 } \\
\text { (I86) }\end{array}$ \\
\hline \multicolumn{12}{|c|}{ Etniciteit ${ }^{3}$} \\
\hline $\begin{array}{l}\text { Etnisch- } \\
\text { cult. } \\
\text { meerder- } \\
\text { heid }\end{array}$ & $73, \mathrm{I}$ & 98,3 & 97,8 & 94,4 & $9^{8,7}$ & $95, \mathrm{I}$ & $97, \mathrm{I}$ & - & 97,8 & 97,0 & $9 \mathrm{I}, \mathrm{I}$ \\
\hline $\begin{array}{l}\text { Etnisch- } \\
\text { cult. min- } \\
\text { derheid }\end{array}$ & 26,9 & $\mathrm{I}, 7$ & 2,2 & 5,6 & $\mathrm{I}, 3$ & 4,9 & 2,9 & - & 2,2 & 3,0 & 8,9 \\
\hline Totaal & $\begin{array}{l}\text { IOO } \\
\text { (I824) }\end{array}$ & $\begin{array}{l}\text { I00 } \\
(692)\end{array}$ & $\begin{array}{l}\text { IOO } \\
(325)\end{array}$ & $\begin{array}{l}\text { I00 } \\
(673)\end{array}$ & $\begin{array}{l}\text { IOO } \\
\text { (310) }\end{array}$ & $\begin{array}{l}\text { IOO } \\
(244)\end{array}$ & $\begin{array}{l}\text { I0O } \\
(244)\end{array}$ & - & $\begin{array}{l}\text { IO० } \\
(89)\end{array}$ & $\begin{array}{l}\text { IOO } \\
\text { (IOI) }\end{array}$ & $\begin{array}{l}\text { I00 } \\
(79)\end{array}$ \\
\hline
\end{tabular}

Noten. De getallen tussen haakjes zijn de absolute aantallen; de percentages bij etniciteit beperken zich tot het binnenlands nieuws $(n=202 \mathrm{I})$.

${ }^{\mathrm{I}} \chi^{2}(20)=39 \mathrm{I}, 5 \mathrm{I} * * * ;{ }^{2} \chi^{2}$ (IO) $=$ II $57,88 * * * ; 3 \chi^{2}(9)=557, \mathrm{I} 8 * * *$ met $* * * * 0.00 \mathrm{I}$

Welzijn blijkt in de Vlaamse pers een jongerenthema te zijn: jongeren zijn er het meest proportioneel in vertegenwoordigd (tabel 2), alsook komen er beduidend meer jongeren (II,8\%) in voor in vergelijking met ouderen $(3,2 \%)$ en volwassenen (3,7\%). Ouderen komen daarnaast het meest voor in nieuws over rampen en mobiliteit (tabel 2). De leeftijdsgroepen blijken, afhankelijk van het nieuwsthema, significant anders te worden verdeeld, $\chi^{2}(20)=39 \mathrm{I}, 5 \mathrm{I} ; p<.00 \mathrm{I}$. Vlaamse journalisten voerden in alle nieuwsthema's meer dan zeven op acht volwassen actoren op, dit in tegenstelling tot de reële sleutel van drie op vijf $\left(\mathrm{H}_{4}\right)$. 
Volwassenen domineren als nieuwsbron sterk het nieuws (Нı): dit is bij uitstek het geval voor elitebronnen (tabel 3). Ook als getuige komen ruim 20\% meer volwassenen in verhouding tot hun reële aandeel in het Vlaamse nieuws aan bod. Bij de 'vox populi' heeft de journalist min of meer een vrije keuze en zou dus naar verwachting de weerspiegelingshypothese het duidelijkst moeten worden bevestigd. Hoewel jongeren hier het meest proportioneel het woord krijgen $(\mathrm{I} 2,4 \%)$, zijn iets meer dan vier op vijf personen volwassen. De leeftijdsgroepen zijn significant verschillend verdeeld over de drie categorieën van nieuwsbronnen heen, $\chi^{2}(4)=260,47 ; p<$. . o I. Zowel als elitebron, getuige als vox pop komen disproportioneel meer volwassenen aan het woord in de Vlaamse pers $\left(\mathrm{OV}_{5}\right)$. Dit beeld verschilt niet wanneer het sportnieuws achterwege wordt gelaten, ook dan worden jongere en oudere nieuwsbronnen sterk ondervertegenwoordigd (tabel 3).

TABEL 3. Frequentie (in percentages) van categorieën nieuwsbronnen volgens leeftijd, gender en etniciteit in Vlaamse krantenartikelen met sport $(N=4800)$ versus zonder sport $(n=3431)$

\begin{tabular}{|c|c|c|c|c|c|c|c|}
\hline & & \multicolumn{3}{|l|}{ Met sport } & \multicolumn{3}{|c|}{ Zonder sport } \\
\hline & & Elitebron & Getuige & Vox pop & Elitebron & Getuige & Vox pop \\
\hline \multirow[t]{4}{*}{ Leeftijd $^{I}$} & Jongeren & 0,4 & 6,8 & $\mathrm{I} 2,4$ & 0,3 & 6,5 & $\mathrm{I} 2,5$ \\
\hline & Volwassenen & 97,8 & 86,5 & 82,3 & 98,0 & 86,4 & $8 \mathrm{I}, 7$ \\
\hline & Ouderen & $\mathrm{I}, 8$ & 6,8 & 5,3 & $\mathrm{I}, 7$ & $7, \mathrm{I}$ & 5,8 \\
\hline & Totaal & $\begin{array}{l}\text { I00 } \\
\text { (3909) }\end{array}$ & $\begin{array}{l}\text { IOO } \\
\text { (3II) }\end{array}$ & $\begin{array}{l}\text { IOO } \\
\text { (II3) }\end{array}$ & $\begin{array}{l}\text { I00 } \\
\text { (3094) }\end{array}$ & $\begin{array}{l}\text { I00 } \\
\text { (294) }\end{array}$ & $\begin{array}{l}\text { IO० } \\
\text { (IO4) }\end{array}$ \\
\hline \multirow[t]{3}{*}{ Gender $^{2}$} & Mannen & 83,4 & 47,7 & 66,7 & 78,7 & 46,9 & 67,5 \\
\hline & Vrouwen & I6,6 & 52,3 & 33,3 & $2 \mathrm{I}, 3$ & $53, \mathrm{I}$ & 32,5 \\
\hline & Totaal & $\begin{array}{l}\text { IOO } \\
\text { (4I59) }\end{array}$ & $\begin{array}{l}\text { I00 } \\
(354)\end{array}$ & $\begin{array}{l}\text { I0० } \\
\text { (I29) }\end{array}$ & $\begin{array}{l}\text { I00 } \\
(3098)\end{array}$ & $\begin{array}{l}\text { I0O } \\
(335)\end{array}$ & $\begin{array}{l}\text { IOO } \\
\text { (I20) }\end{array}$ \\
\hline \multirow[t]{3}{*}{ Etniciteit ${ }^{3}$} & Etnisch-cult. meerderheid & 95,6 & 94,8 & 95,8 & 98,5 & 94,6 & 95,5 \\
\hline & Etnisch-cult. minderheid & 4,4 & 5,2 & 4,2 & $\mathrm{I}, 5$ & 5,4 & 4,5 \\
\hline & Totaal & $\begin{array}{l}\text { IoO } \\
\text { (I793) }\end{array}$ & $\begin{array}{l}\text { IOO } \\
\text { (I55) }\end{array}$ & $\begin{array}{l}\text { I0० } \\
\text { (48) }\end{array}$ & $\begin{array}{l}\text { IOO } \\
\text { (1385) }\end{array}$ & $\begin{array}{l}\text { I00 } \\
\text { (I48) }\end{array}$ & $\begin{array}{l}\text { IOO } \\
\text { (44) }\end{array}$ \\
\hline
\end{tabular}

Noten. De getallen tussen haakjes zijn absolute aantallen; de percentages bij etniciteit beperken zich tot het binnenlands nieuws $(n=202 \mathrm{I})$.

${ }^{\mathrm{I}}$ Met sport, $\chi^{2}(4)=260,47 * * *$, zonder sport, $\chi^{2}(4)=257,28 * * * ;{ }^{2}$ met sport, $\chi^{2}(2)=277,00 * * * ;$; zonder sport, $\chi^{2}(2)=\mathrm{I} 68,34 * * * ; 3$ met sport, $\chi^{2}(2)=0,20 \mathrm{I}$; zonder sport, $\chi^{2}(2)=\mathrm{I} 2,06 *$ met $* * * p<.00 \mathrm{I}$.; $* p<.05$

\section{Gender}

Van de I2.377 actoren van wie gender werd bepaald, is 83,7\% man en $16,3 \%$ vrouw. Specifiek voor nieuwsbronnen $(n=4642)$ wordt een gelijkaardige man-vrouwverdeling teruggevonden, hoewel hier iets meer vrouwen (19,8\%) een stem krijgen in verhouding tot mannen $(80,2 \%)$. De Simpson's $D$ is 0,27 voor alle actoren en 0,32 voor 
de nieuwsbronnen. In werkelijkheid is dit 0,50 , hetgeen betekent dat de pers I, 9 keer minder divers is wat betreft actoren en I, 6 keer wat betreft nieuwsbronnen. Wordt er enkel gekeken naar de actoren in het binnenlandse nieuws $(n=4849$, 96,5\% van de actoren), dan blijft de verhouding ook min of meer gelijk: $82,3 \%$ mannen versus $17,7 \%$ vrouwen. In de Vlaamse dagbladen worden mannen met meer dan $30 \%$ oververtegenwoordigd in verhouding tot de demografische werkelijkheid $(\mathrm{H} 2)$.

Tabel 2 toont aan dat vrouwen het meest proportioneel worden vermeld in de thema's welzijn, en cultuur en entertainment. Mannen domineren de thema's sport en politiek. Mannen en vrouwen worden significant anders verdeeld over de verschillende nieuwsthema's heen, $\chi^{2}$ (IO) $=$ II 57,$88 ; p<.00$. Het thema welzijn kan getypeerd worden als 'vrouwelijk': bijna twee op vijf actoren binnen dit thema is een vrouw, dit in tegenstelling tot de verhouding van één op vijf vrouwen in de gehele berichtgeving. Ook cultuur en entertainment is een 'vrouwelijk' nieuwsthema: verhoudingsgewijs komen er iets meer vrouwen in voor en bijna twee op zes van alle vrouwen $(3 \mathrm{I}, 6 \%)$ komen in dit thema aan bod. Sport en politiek zijn 'mannenthema's': er komt namelijk maximaal één op zes vrouwen binnen deze thema's voor $\left(\mathrm{H}_{4}\right)$.

Mannen krijgen disproportioneel vaker dan vrouwen het woord in de Vlaamse pers $(\mathrm{H} 2)$. Tabel 3 geeft aan dat deze dominantie van toepassing is voor elitebronnen, en in mindere mate voor 'vox populi'. De getuigen worden daarentegen licht gedomineerd door vrouwen. Vrouwen en mannen zijn significant anders over de drie groepen nieuwsbronnen verdeeld, $\chi^{2}(2)=277,00 ; p<.00$ I. Als het sportnieuws uit de steekproef wordt gelaten, liggen de cijfers in dezelfde lijn (tabel 3). Mannen domineren dus het Vlaamse nieuws als elitebron en vox pop, terwijl vrouwen in verhouding tot mannen iets meer het woord krijgen als getuige $\left(\mathrm{OV}_{5}\right)$.

\section{Etniciteit}

Deze analyse beperkt zich zoals eerder aangegeven tot de binnenlandse nieuwsverslaggeving $(n=202 \mathrm{I})$. Van de actoren $(n=458 \mathrm{I})$ bij wie etniciteit werd ingeschat, behoort $87,3 \%$ tot een etnisch-culturele meerderheid en $12,7 \%$ tot een etnischculturele minderheid. In verhouding tot de $9 \%$ etnisch-culturele minderheden in de Belgische bevolking is dit een relatief hoog cijfer. Dit blijkt grotendeels te wijten aan de sterke oververtegenwoordiging van etnisch-culturele minderheden in het sportnieuws (tabel 2). Wordt sportnieuws uit de steekproef gefilterd $(n=2757)$, dan worden er nog 3,3\% etnisch-culturele minderheden vermeld. Dit biedt ten dele een verklaring waarom publiekskranten significant meer etnisch-culturele minderheden opvoeren dan kwaliteitskranten, immers, De Morgen en De Tijd hebben geen specifieke sportpagina's. Binnen de nieuwsbronnen in het gehele binnenlandse nieuws ( $n=1996)$ behoort $95,5 \%$ tot de etnisch-culturele meerderheidsgroep en $4,5 \%$ tot een etnisch-culturele minderheidsgroep. Vlaamse journalisten vermelden dus meer 
etnisch-culturele minderheden in hun artikelen in vergelijking met de Belgische bevolkingscijfers, maar voeren ze disproportioneel weinig op als nieuwsbron $\left(\mathrm{H}_{3}\right)$. De Simpson's $D$ is in werkelijkheid o,16, terwijl in de pers dit 0,22 is voor alle actoren en 0,09 specifiek voor de nieuwsbronnen. De kranten vermelden etnischculturele minderheden dus meer divers $(0,74$ keer), maar geven ze I,9 keer minder divers het woord.

Etnisch-culturele minderheden worden enkel binnen het sportnieuws disproportioneel vaker opgevoerd, en in het thema rechten en vrijheden worden ze evenredig met hun werkelijke aandeel vermeld (tabel 2). Doorheen de verschillende nieuwsthema's wordt de etnisch-culturele minderheidsgroep in verhouding tot de etnischculturele meerderheidsgroep significant verschillend verdeeld, $\chi^{2}(9)=557, \mathrm{I} 8$; $p<.00$ I. In de lijn met voorgaand onderzoek (Avraham, 20I3) komen etnisch-culturele minderheden vooral in sportnieuws voor $(84,2 \%)$. Wordt sportnieuws uit de steekproef gehaald, dan duiken van de 3,3\% etnisch-culturele minderheden $(n=92)$ meer dan twee op vijf $(4 \mathrm{I}, 3 \%)$ op in nieuws over gerecht en criminaliteit. Naast sportnieuws kunnen de thema's rechten en vrijheden, en gerecht en criminaliteit als etnisch-culturele minderheidsthema's worden bestempeld ( $\left.\mathrm{H}_{4}\right)$.

Tabel 3 toont aan dat etnisch-culturele minderheden zowel als elitebron, getuige en vox pop disproportioneel weinig het woord krijgen, er is dan ook geen significant verschil tussen de drie typen nieuwsbronnen, $\chi^{2}(2)=0,20 \mathrm{I} ; p<.05$. Als vox pop krijgen etnisch-culturele minderheden het minst het woord, dit in tegenstelling tot de verwachting, aangezien journalisten hier logischerwijs meer mogelijkheden hebben om etnisch-culturele minderheden in het nieuws te betrekken. Wordt het sportnieuws uit de steekproef gelaten, dan blijken etnisch-culturele minder- en meerderheden wel significant anders te zijn verdeeld voor de drie bronnencategorieën, $\chi^{2}(2)$ $=\mathrm{I} 2,06 ; p<.05$. Vooral als elitebron krijgen etnisch-culturele minderheden dan nauwelijks een stem (I,5\%). Over het algemeen blijken Vlaamse journalisten weinig nieuwsbronnen van etnisch-culturele minderheidsgroepen aan het woord te laten $\left(\mathrm{OV}_{5}\right)$.

\section{Conclusies}

Deze studie meet de demografische diversiteit van de Vlaamse kranten op het vlak van leeftijd, gender en etniciteit. In de lijn met voorgaand onderzoek (o.a. Ter Wal et al., 2005) laten Vlaamse journalisten disproportioneel weinig jongeren, ouderen, vrouwen, en etnisch-culturele minderheden in verhouding tot de werkelijkheid aan het woord. Dit weinig demografisch divers beeld blijkt voor alle kranten op te gaan, aangezien de verschillen tussen de dagbladen onderling eerder klein zijn. Onafhankelijk van welk merk de Vlaamse lezer prefereert, krijgt hij of zij dus geen reflectie van de maatschappelijke diversiteit in de nieuwsinhoud voorgeschoteld. Opvallend 
is daarnaast dat Vlaamse kranten in tegenstelling tot een positieve tendens in Amerikaanse nieuwsmedia (Avraham, 2013) vrouwen en etnisch-culturele minderheden heel weinig als bron opvoeren, en in beeld brengen in typische nieuwsverhalen zoals welzijn of sport.

Grotendeels zijn de resultaten te verklaren vanuit de journalistieke reflex om elitebronnen in het nieuws te betrekken. In de Vlaamse pers is er een duidelijke oververtegenwoordiging van elitebronnen $(88,7 \%)$ vast te stellen. Dit type bronnen is in realiteit niet gelijk verdeeld wat leeftijd, gender en etniciteit betreft. Elitebronnen worden immers vaak omwille van een beroepsgerelateerde expertise aan het woord gelaten. Op die manier worden jongeren en ouderen structureel uitgesloten, want ze behoren niet (meer) tot de actieve bevolking. Echter, ook als getuige en vox pop worden jongeren en ouderen in vergelijking met de realiteit sterk ondervertegenwoordigd. Voor de groep jongeren zijn er complicerende factoren bij verslaggeving met kinderen die dit verklaren: vanaf een bepaalde leeftijd kunnen ze verwoorden wat ze meemaken en er gelden bovendien juridische beperkingen voor het citeren van minderjarigen.

In werkelijkheid blijken ook iets meer mannen (54,5\%) dan vrouwen in België te werken (FOD Economie, 20I3). Daarnaast zijn minder vrouwen actief in de zakenwereld, de advocatuur of de politiek. Laat dit nu net de beroepscategorieën zijn die traditioneel meer in het nieuws komen. In België zijn er bijvoorbeeld slechts $20 \%$ vrouwelijke bedrijfsleiders, 23,3\% vrouwelijke directeurs in de privésector en 48,7\% advocates actief (FOD Economie, 20IO). Ondanks deze nuancering, worden vrouwen in de Vlaamse kranten nog ondervertegenwoordigd: er kwamen slechts I०,9\% vrouwelijke bedrijfsleiders en directeurs, en I2,6\% advocates aan het woord. Politica's worden minder sterk ondervertegenwoordigd: 27,2\% binnenlandse politica's in het nieuws in verhouding tot 39,1\% vrouwelijke verkozenen in alle Belgische parlementen (Sliwa, Meier, \& Thijssen, 20I0). Vrouwen worden ook het meest in een 'vrouwelijk' nieuwsthema als welzijn opgevoerd, terwijl het minst in een eerder 'mannelijk' thema als politiek. Dit komt overeen met Vlaams televisienieuwsonderzoek (De Swert \& Hooghe, 20I0).

Etnisch-culturele minderheden blijken in de berichtgeving wel meer te worden vermeld (I2,7\%) in verhouding tot hun aandeel in de maatschappij (9\%). Echter, slechts $4,5 \%$ etnisch-culturele minderheden krijgen het woord. Daarenboven is de oververtegenwoordiging uitsluitend te wijten aan het sportnieuws. Worden de sportpagina's uit de steekproef gehaald, dan komen er slechts 3,3\% etnisch-culturele minderheden in het nieuws voor. Met andere woorden, vergelijkbaar met ander Vlaams onderzoek (o.a. Devroe, 2007) komen etnisch-culturele minderheden, met uitzondering van de 'usual suspects' (als sportlui, criminelen of migranten), nauwelijks aan bod in de Vlaamse pers, laat staan dat ze het woord krijgen. 
De algemene conclusie luidt dat het nieuws de bestaande machtsrelaties en ongelijkheden in de maatschappij bestendigen. Nochtans geven bijvoorbeeld Turkse en Marokkaanse Belgen aan dat een proportioneel voorkomen van leden van hun 'groepen' in diverse nieuwsonderwerpen en in diverse rollen hen zouden helpen zich meer te identificeren met de samenleving (El Sghiar \& d'Haenens, 20II). Het Vlaamse perslandschap biedt dus anno 20І2 ruimte voor meer diversiteit: vrouwen, jongeren en ouderen worden sterk ondervertegenwoordigd, en etnisch-culturele minderheden worden bijna uitsluitend geassocieerd met sport, gerecht en criminaliteit, en rechten en vrijheden. Ook wanneer de Vlaamse krantenjournalisten een grotere keuzevrijheid hebben bij de 'vox populi', komen disproportioneel vaak volwassen mannen van de etnisch-culturele meerderheidsgroep aan bod. Een dergelijke grote kloof tussen de maatschappelijke en voorgestelde werkelijkheid in het nieuws lijkt moeilijk te rechtvaardigen: zeven op acht personen in het nieuws zijn volwassen in tegenstelling tot de reële verhouding van drie op vijf, er worden $30 \%$ meer mannen in het nieuws aan bod gelaten dan er in werkelijkheid zijn, en slechts 50\% van de etnisch-culturele minderheden in de werkelijkheid krijgen in het Vlaamse nieuws het woord.

Toch dienen deze resultaten te worden genuanceerd. Zo kan de operationalisering van etniciteit vragen oproepen. Zo is het bepalen van etniciteit op basis van naam slechts een inschatting, waarbij hoofdzakelijk de generatielijn langs vaderskant in rekening wordt gebracht. Maar ook het indelen van etniciteit op basis van nationaliteit heeft beperkingen. Iemand die bijvoorbeeld expliciet als Belg in de krant wordt vermeld, kan toch tot de etnische minderheidsgroep behoren doordat een van de (voor)ouders een niet-EU-I5-achtergrond heeft. Ondanks deze lacunes is getracht zo goed mogelijk etniciteit op basis van de beschikbare informatie te detecteren.

Naast de beperkingen over de operationalisering van etniciteit, kan men zich afvragen of het überhaupt wenselijk is om iemands etnisch-culturele identiteit in te schatten. Toch is het aannemelijk dat vele mensen, onder wie journalisten en krantenlezers, impliciet een opdeling maken op basis van etnisch-culturele achtergrond. Vanuit die optiek is het coderen van etniciteit van actoren in het nieuws relevant.

Een andere nuance is het feit dat het demografische cijfer van etnisch-culturele minderheden gebaseerd is op personen die in België wonen en niet in een EU-I5land geboren zijn, wat niet volledig overeenstemt met de vooropgestelde definitie. Er zijn immers geen bevolkingscijfers beschikbaar die de etniciteit van (voor)ouders mee in rekening brengen. De beperking tot binnenlandse nieuwspagina's garandeert evenmin dat vermelde personen in het nieuws in België wonen. Zo wordt een toerist met een niet-westers klinkende naam in de binnenlandse nieuwspagina's beschouwd als een etnisch-culturele minderheid in België. Daarnaast worden alle Engelstalige namen onder EU-I5 gerekend, waardoor onder meer Australiërs of Amerikanen de groep etnisch-culturele meerderheden doen vergroten. 
De operationalisering van diversiteit als demografische diversiteit heeft dus haar beperkingen, en wordt dan ook als theoretische inschatting vooropgesteld voor de mate waarin elke groep in de samenleving al dan niet evenredig in de Vlaamse pers vertegenwoordigd is. Een meer diverse nieuwsverslaggeving zou impliceren dat journalisten gericht en bewust naar vrouwen, jongeren, ouderen en etnischculturele minderheden als (elite)bron op zoek gaan. Dit lijkt ogenschijnlijk in strijd met het principe dat journalisten de 'feiten' voor zich moet laten spreken en deze niet naar hun hand mogen zetten. Hieruit zou immers een sociaal engagement kunnen spreken dat ook te verantwoorden is. De eerste houding voelt echter als veiliger aan en blijkt ook de voorkeur te hebben van journalisten. Dit houdt verband met de reflectionistische versus constructivistische visie op mediarepresentatie: in welke mate moeten journalisten de werkelijkheid reflecteren of hebben ze de taak de werkelijkheid mee te construeren door bijvoorbeeld etnisch-culturele minderheden een stem te geven? In vervolgonderzoek zal aan journalisten aan de hand van semi-gestructureerde diepte-interviews worden gevraagd hoe zij deze vormen van diversiteit in hun dagelijkse nieuwspraktijk al dan niet inpassen. Dit zal inzicht geven in welke mate (demografische) diversiteit als journalistieke richtlijn wenselijk, zinvol en ook haalbaar is.

\section{Literatuur}

Albæk, E. (20II). The interaction between experts and journalists in news journalism. Journalism, 12(3), $335-348$.

Avraham, E. (2013). Changes in the news representation of minorities over the course of 40 years of research. In The International Encyclopedia of Media Studies. Retrieved from http://online library.wiley.com/doi/ıo.1002/978I44436I506.wbiemso64/pdf.

De Swert, K., \& Hooghe, M. (20I0). When do women get a voice? Explaining the presence of female news sources in Belgian news broadcasts (2003-5). European Journal of Communication, 25(I), 69-84.

Devroe, I. (2007). Gekleurd nieuws? De voorstelling van etnische minderheden in het nieuws in Vlaanderen. Context, methodologische aspecten en onderzoeksresultaten. Gent: Vakgroep Communicatiewetenschappen, Universiteit Gent.

Devroe, I., Driessens, O., \& Verstraeten, H. (2010). 'Minority report': ethnic minorities' diasporic news consumption and news reading. In S. Van Bauwel, E. Van Damme \& H. Verstraeten (Eds.), Diverse mediawerelden: hedendaagse reflecties gebaseerd op het onderzoek van Frieda Saeys (pp. 233-249). Gent: Academia Press.

Duncan, J., \& Reid, J. (2013). Toward a measurement tool for the monitoring of media diversity and pluralism in South Africa: A public-centred approach. Communicatio, 39(4), 483-500.

El Sghiar, H., \& d'Haenens, L. (20II). Publieke televisie en identificatie. Familieonderzoek naar Vlaamse burgers met Marokkaanse en Turkse achtergrond. Tijdschrift voor Communicatiewetenschap, 39(2), $38-56$.

Eurostat (2012). Database of population data. Opgehaald 3 januari, 20I3, van http://epp.eurostat.ec.europa.eu/portal/page/portal/population/data/database

FOD Economie (2010). Beroepen (top 100) in België volgens geslacht. Raadpleegbaar via: http://statbel.fgov.be/nl/modules/publications/statistiques/arbeidsmarkt_levensomstandigheden/

Top_Ioo_beroepen.jsp

FOD Economie (2013). De Belgische arbeidsmarkt in 2012. Raadpleegbaar via: http://statbel.fgov.be/nl/ binaries/analyse_nl_tcm325-2388I2.pdf 
Groeling, T. (2013). Media bias by the numbers: Challenges and opportunities in the empirical study of partisan news. Annual Review of Political Science, 16(I), I29-I5I.

Hayes, A. F., \& Krippendorff, K. (2007). Answering the call for a standard reliability measure for coding data. Communication Methods and Measures, 1, 77-89.

Hussain, M. (2000). Islam, media and minorities in Denmark. Current Sociology, 48(4), 95-II6.

Len-Ríos, M. E., Rodgers, S., Thorson, E., \& Yoon, D. (2005). Representation of women in news and photos: Comparing content to perceptions. Journal of Communication, 55(I), I52- I68.

McDonald, D., \& Dimmick, J. (2003). The conceptualization and measurement of diversity. Communication Research, 30(I), 60-79.

McQuail, D. (I992). Media performance: Mass communication and the public interest. London: Sage.

Matud, M. P., Rodríguez, C., \& Espinosa, I. (20II). Gender in Spanish daily newspapers. Sex Roles, 64(3-4), 253-264.

Napoli, P. M. (I999). Deconstructing the diversity principle. Journal of Communication, 49(4), 7-34.

Orgad, S. (2012). Media representation and the global imagination. Cambridge: Polity Press.

Ponte, C. (2007). Mapping news on children in the mainstream press. European Societies, 9(5), 735-754.

Riffe, D., Lacy, S., \& Fico, G. F. (I998). Analyzing media messages. Using quantitative content analysis in research. Mahwah (New Jersey): Erlbaum.

Silverstone, R. (2008). Media and morality: On the rise of the mediapolis. Cambridge: Polity Press.

Sliwa, S., Meier, P., \& Thijssen, P. (2010). De politieke vertegenwoordiging van vrouwen. Na de verkiezingen van 7 juni 2009. Een objectieve balans van de quota. Brussel: Instituut voor de gelijkheid van vrouwen en mannen.

Ter Wal, J., d'Haenens, L., \& Koeman, J. (2005). (Re)presentation of ethnicity in EU and Dutch domestic news: a quantitative analysis. Media, Culture \& Society, 27(6), 937-950.

Trebbe, J., \& Schoenhagen, P. (20II). Ethnic minorities in the mass media: How migrants perceive their representation in Swiss public television. Journal of International Migration and Integration, 12(4), $4 \mathrm{II}-428$.

United Nations, Department of Economic and Social Affairs, Population Division (20II). World population prospects: The 2010 revision. Raadpleegbaar via: http://www.un.org/esa/population/unpop.htm

Van den Bulck, H., \& Broos, D. (20II). Can a charter of diversity make the difference in ethnic minority reporting? A comparative content and production analysis of two Flemish television newscasts. Communications, 36(2), 195-216.

Van Zoonen, L. (2007) Media, cultuur en burgerschap. Een inleiding. Apeldoorn/Antwerpen: Het Spinhuis.

Vos, D. (20I2). Is gender bias een mythe? Op zoek naar verklaringen voor de beperkte aanwezigheid van vrouwelijke politici in het Vlaamse televisienieuws. Res Publica, 54(2), I93-2I7.

Wauters, K. (20I3). Panelgesprek: wetenschap \& pers, pers \& wetenschap. Brussel: VUB. 